\title{
Policy-makers' views on impact of specialist and advanced practitioner roles in Ireland: the SCAPE study
}

\author{
CECILY BEGLEY RGN, RM, RNT, FFNRCSI, MSc, MA, PhD, FTCD ${ }^{1}$, KATHY MURPHY RGN, BA, MSc, RNT, Dip N, PhD ${ }^{2}$, \\ AGNES HIGGINS RGN, RPN, BNS, MSc, PhD ${ }^{3}$ and ADELINE COONEY RGN, RNT, BNS, MMedSc (Nurs), PhD ${ }^{4}$ \\ ${ }^{1}$ Professor, School of Nursing and Midwifery, Trinity College Dublin, Dublin, ${ }^{2}$ Professor, School of Nursing and \\ Midwifery, National University of Ireland Galway, Galway, ${ }^{3}$ Professor, School of Nursing and Midwifery, Mental \\ Health Nursing, Trinity College Dublin, Dublin and ${ }^{4}$ Senior Lecturer, School of Nursing and Midwifery, National \\ University of Ireland Galway, Galway, Ireland
}

Correspondence

Cecily Begley

School of Nursing and Midwifery

Trinity College Dublin

24 D’Olier Street

Dublin 2

Ireland

E-mail: cbegley@tcd.ie
BEGLEY C. , MURPHY K., HIGGINS A. \& COONEY A. (2012)

\section{Policy-makers' views on impact of specialist and advanced practitioner roles in Ireland: the SCAPE study}

Aim To ascertain and explore the views held by key healthcare policy-makers on the impact of clinical specialist and advanced practice nursing and midwifery roles.

Background Specialist and advanced practice roles are common world-wide and were introduced in Ireland in 2000. After experiencing these roles for a decade, the views of healthcare policy-makers were sought as part of a national evaluation.

Methods A qualitative, descriptive design was used. Following ethical approval, 12 policy-makers were interviewed in 2010, using a six-part interview schedule.

Results Policy-makers believed that specialist and advanced practice roles resulted in better continuity of care, improved patient/client outcomes and a more holistic approach. These clinicians were also said to be leading guideline development, new initiatives in care, education of staff, audit and policy development. They lacked administrative support and research time. Budget cuts and a governmentapplied recruitment moratorium were said to hamper the development of specialist/advanced practice roles.

Conclusion Healthcare policy-makers believe that specialists and advanced practitioners contribute to higher quality patient/client care, particularly at a strategic level.

Implications for nursing management These roles could make an important contribution to future health service developments, particularly in relation to chronic-disease management and community care, where more advanced practitioner posts are required.

Keywords: advanced practice, clinical midwife specialist, clinical nurse specialist, nurse practitioners, qualitative research

Accepted for publication: 28 August 2012

\section{Introduction}

Clinical specialist and advanced practitioner roles exist in most developed countries (Bryant-Lukosius et al.
2004), but the terminology and definitions of each role can differ (Coster et al. 2006, Sheer \& Wong 2008, Kennedy et al. 2011, Kleinpell et al. 2012). In Ireland, the roles were introduced following recommendations 
of the Report of the Commission on Nursing (Government of Ireland 1998), based on detailed literature reviews and international visits to discuss the professional development of nursing and midwifery with experts. The National Council for the Professional Development of Nursing and Midwifery in Ireland (NCNM) was instituted in 1999, funded by the Department of Health, to develop these roles. Clear definitions, approval and accreditation guidelines were developed by the NCNM team, agreed by their Board and published [National Council for the Professional Development of Nursing and Midwifery in Ireland (NCNM) 2008a, b]. Holders of both posts could carry a clinical case-load (e.g. running nurse or midwife-led clinics), but advanced practitioners had more autonomy and were also required to conduct research. Recognizing that Ireland was lagging behind other countries in this area, considerable funding was made available by the Department of Health to support posts.

A major nationwide evaluation of the posts was conducted 2008-10 (Begley et al. 2010), entitled 'Specialist Clinical and Advanced Practitioner Evaluation' study, or 'SCAPE'. In the final phase of this evaluation, policy-makers were interviewed to ascertain their views on the impact of the roles.

\section{Background}

Roles for clinical specialists (CSs) and advanced practitioners (APs) in Ireland are clearly set out by the NCNM (NCNM 2008a, b). This is not the case in other countries, such as the United Kingdom (UK) (Jones 2005, Brook \& Rushforth 2011), New Zealand (Roberts et al. 2011), Australia (Lowe et al. 2012) and Canada (Donald et al. 2010), where calls for role clarity and regulation are common. A recent international web-based survey found that of 23 countries that formally recognized advanced practice nursing roles, only $48 \%$ had renewal or licence maintenance requirements, and $50 \%$ required a Masters degree for initial registration (Pulcini et al. 2010). Clearly defined roles and responsibilities should lead to efficient and effective practice (Jones 2005, Por 2008) that can be measured against the skills, knowledge and qualifications required.

It has been noted in other work in Canada (DiCenso et al. 2010) that the development of advanced practice nursing and midwifery roles can be enabled by a number of factors, most of which occur at governmental or regional level, and are thus governed by policy-makers. In Ireland, a threatened strike of nurses and midwives in the mid-90s forced the Government to examine ways of responding to their demands for increased recognition. The policy-making 'stages' (Dorey 2005) of agenda-setting and recognition of the problem thus came from the nursing and midwifery professions.

Work in the UK has demonstrated that policy-making can occur at different levels. A detailed analysis of the way in which health policies implemented by the UK Government were translated into community nursing practice showed that four key variables identified by the authors as responsible for success of policy implementation (Bergen \& While 2005) could be seen to have led to the success of the introduction of clinical specialists/ advanced practitioners in Ireland also. These were: the degree to which guidance on the policy was given clearly (clear criteria for clinical specialists and advanced practitioners were laid down by the NCNM); the extent to which professional nursing values concurred with the stated policy (the introduction of specialist and advanced posts was welcomed by nurses and midwives in Ireland); the presence of practices and policies at local level (these were well developed prior to the introduction of new posts, due to NCNM's regulations); and the personal vision of the nurses involved (as with many new initiatives, the incumbents of the new posts were the young leaders of the professions).

\section{Aim}

The aim of this study was to ascertain and explore the views held by key healthcare policy-makers on the impact of clinical specialist and advanced practice nursing and midwifery roles on healthcare.

\section{Methods}

A qualitative, descriptive design was used. Ethical approval was granted by the Research Ethics Committee of the Faculty of Health Sciences, Trinity College Dublin. Written consent was obtained by email, or face-to-face, before each interview. To protect participants' identity, digital recordings and transcriptions were allocated code numbers. The list of names and corresponding identifiers was stored separately and securely. Data files were password-protected.

\section{Recruitment and sample}

The sole inclusion criterion was that participants were responsible for policy-making for nursing/midwifery in the Department of Health, Health Service Executive (HSE), or relevant organisations that govern or shape 
Irish health policy, including trade unions, professional and regulatory bodies. To preserve anonymity, the precise roles of participants are not given but examples might include: Principal Officers or Nursing Advisors in the Department of Health, Nursing Advisors or Chief Executive/Director of Nursing or Midwifery/Clinical Leaders of care pathways in the HSE, Education Officers/Executive Officers at all levels of An Bord Altranais (the Irish Nursing Board), Advisors/Education Officers in the trade unions. Fifteen people were identified and purposively sampled, of whom 12 agreed to be interviewed. All 12 participants were experienced in their roles and had been in post for a number of years, the majority since before the clinical specialist/advanced practitioner posts were introduced. Approximately half came from, or worked in, a clinical healthcare role and slightly more than half were responsible for broad healthcare policy, in addition to nursing and midwifery. An invitation letter, information and consent form were emailed to all, and those willing and able to participate provided telephone numbers and times for interview.

\section{Data collection methods}

Semi-structured, recorded interviews were undertaken by all authors, all of whom are experienced interviewers. The number of interviewers was necessary to cover the two professions, and most disciplines of nursing, with an interviewer known in that field. An interview schedule, developed from initial findings of the national study (Begley et al. 2010), was used to ensure comparability between interviews (Table 1 ). Interviews were conducted in either a telephone or face-to-face format, and at a place and time, chosen by participants, in July-September 2010. The duration of interviews was 25-62 minutes, average 40 minutes $(S D=12.5)$.

\section{Data analysis}

Analysis was by the constant comparative method, involving comparison of multiple datasets for interchangeability of indices (Glaser 1978). Interviews were transcribed and coded using headings from the interview schedule as a guide. Initial findings were tested with subsequent participants. Contradictory evidence was sought by questioning apparent truths in the final few interviews (Mays \& Pope 2000). Although the participant numbers may have been too small for full theoretical saturation, final interviews were used to test emerging themes.

\section{Rigour}

Interview transcripts were returned to participants on request, for confirmation that their views were

\section{Table 1}

Interview schedule

The Clinical Specialist or Advanced Practitioner role

Have you noticed any difference in the service provided nationally, or in the professional standing of nurses and midwives, since the CNS/ CMS/ANP/AMPs were appointed?

Please comment on the clinical practice role

Managing a case-load, e.g. assessing, diagnosing, managing the care pathway, working within a multi-disciplinary team, referral to and from the CS/AP

Service provision, e.g. health promotion, physical interventions, psychosocial interventions

Please comment on the clinical leadership role

Guideline development, e.g. led by the CS/AP, or as member of the development team

Acting as a resource, e.g. providing clinical supervision, membership of committees, acting as a consultant, education of other staff, mentorship

Service development, e.g. early booking schemes, improved charts, initiatives in care

Please comment on the professional leadership role

Impacting on knowledge, skills and practice of health care practitioners outside their service, e.g. teaching on existing undergraduate and postgraduate education programmes and designing new programmes.

Influencing practice through the development of national and international clinical practice guidelines

Influencing nursing/midwifery and health care agendas at national or international level, e.g. influencing nursing/midwifery policy and practice, through membership of national or, possibly, international committees.

Please comment on the research and audit role

General level of activity, e.g. audit, research, using research-based guidelines and networking with each other.

Difference between CS and AP roles, e.g. CNS/CMS in general have few research skills (few hold an MSc). Research is not part of their job description. All APs must hold an MSc and research is part of their role.

Access to/use of data, e.g. APs, in particular, have a lot of data collected

Resources, e.g. training, protected time, support from other team members, access to computers/internet.

Please comment on the financial implications of the role

CS/AP salaries cost less than those of non-consultant doctors but cost more than salaries of staff nurses or midwives. 
represented. Author CB documented analysis of her interviews first. This was checked by the other authors in the process of 'peer debriefing', in which they had independently analysed 2-3 transcripts each and then compared findings (Kitto et al. 2008). Deviations were resolved by discussion. The process was made transparent by documenting a systematic account of the fieldwork, including raw and coded data (Hall \& Callery 2001). The viewpoint of all interviewers (positively disposed, generally, to CS/AP roles) is acknowledged as a factor that may have influenced data collection, analysis and interpretation (Kitto et al. 2008). However, almost all participants' responses appeared even more positive, and many previously unknown benefits of the roles emerged during the interviews.

\section{Findings}

Findings are grouped under the six key headings from the interview schedule (Table 1), with two extra headings, derived from policy-makers' comments: 'Challenges to introduction of CS/AP roles' and 'Future directions for CS/AP roles'.

\section{Participants' overall opinions of CSs and APs}

Most participants spoke favourably about the clinical specialist and advanced practitioner roles, describing them as 'providing the vision for a new generation of nurses' (PM5), 'well respected' (PM6) and 'absolutely key to a modern health system' (PM3). They were described as having 'made an enormous contribution' (PM7), in that they gave 'added value' (PM8), 'provide continuity' (PM9) and played 'a very key influential role' (PM10). The benefits of the roles were seen to be recognized by clinicians, managers and serviceusers also, which was felt to be important:

'There's a... huge drive in each programme team to include specialist nurses and practice nurses and this was coming from the medical, medicine itself'.

(Policy-maker 1)

'Where there are specialist roles, the positive feedback we have from patients... is very encouraging'.

(Policy-maker 3)

'The overall improvement for... children and their families, has been commented on within that service'.

(Policy-maker 10)
Some differentiation was noted between the impacts of advanced practice and specialist roles. Two participants commented that, while the impact of advanced practice was always consistent, there was more variability in the clinical specialist role. Concerns related, first, to a lack of governance structures when the roles were first developed, resulting in a diversity within the clinical specialist role. However, participants also acknowledged considerable improvement in terms of new clinical specialist developments recently:

'I think for some clinical nurse specialists, particularly those... [appointed] in the early days... they perhaps did not have to go through as rigorous a process as those in recent times'.

(Policy-maker 10)

'In general nursing... there was much more development in the job description [for CS]... individuals had to sit down, construct a role, find a place for themselves within the service, identify where it could be a nurse-led service and take it as a much broader newer initiative. I couldn't say the same thing happened at that time in mental health... However, since then there have been some bigger developments... we would have clinical nurse specialists (CNSs) in eating disorders...in CBT [cognitive behavioural therapy]... in relation to childhood, adolescent psychiatry, psychiatry of later life, etc. And they have all been very positive'.

(Policy-maker 12)

One participant believed that the 'advanced role' label in relation to midwifery was merely an acknowledgement of the autonomous midwife's role that existed already:

'... the midwives... I've always had the view that they were advanced practitioners and should be paid as such, particularly as midwives are different from... nurses in that they are actually taking... clinical decisions, rather than just implementing decisions that other people take'

(Policy-maker 7)

\section{Clinical practice role}

The participants spoke highly of the clinical specialists' and advanced practitioners' input into clinical practice, particularly noting psychosocial and practical skills, and improved patient/client outcomes:

'It's the nurse who will tell her the quality pieces around how she manages. I think medics aren't 
good at the caring piece, psychosocial piece... if you talk to the consultant, you'll get the highpowered stuff but you rarely get a lot of detail on the real nitty-gritty, important day-to-day issues'.

(Policy-maker 2)

The importance of the CNS role within the multidisciplinary team was noted by policy-makers. Specifically, they highlighted the important leadership role of the CNS, particularly when collaborating with other health professionals. One participant suggested that 'Every team should have at least one CNS' (PM4). Other respondents commented:

'A specific skill set in relation to diagnosing... multidisciplinary team-working ... I think that's an absolute strength of clinical nurse specialists and advanced nurse practitioners (ANPs)'.

(Policy-maker 6)

'CNSs appointed in more recent years... would be much more strategic... It's not a simple case of calling out to someone, assessing them, titrating their medication... or referring back to the... doctor. They have become much more autonomous... they've developed many more leadership roles within teams'.

(Policy-maker 12)

One benefit of the advanced practitioner roles, in particular, was seen to be swifter access to services, which allowed service-users to be assessed, diagnosed, treated and discharged from the system, thus decreasing waiting lists and waiting times in clinics:

'The biggest problem we have in our health services is actually accessing it... assessment and diagnostics... they are the two things that are initially blocking people getting into the health services'.

(Policy-maker 1)

'It's a much cleaner, swifter way... being assessed, having treatment and being discharged and for the service it means that you don't have these long waiting lists... that's where ANPs have excelled'.

(Policy-maker 12)

'They made differences in relation to cutting... waiting times and... streamlining the work that they do...'.

(Policy-maker 6)
In addition, the clinical specialists and advanced practitioners were praised for their greater organisational skills, better continuity of care and follow-up, leading to improved care and compliance compared with the care given by doctors:

'I would have seen them... in the gastro surgery running nurse-led constipation clinics... developing... child friendly tools... They [CNS] have a great ability to manage... keep records... They do flowcharts... of people who are due to come in and where are they. Doctors don't do that particularly well, I think'.

(Policy-maker 2)

'Chronic-disease management in particular, with continuity being provided by advanced nurse practitioners and clinical nurse specialists... you can get better outcomes... that continuity of care is very important in terms of patient compliance and all that'.

(Policy-maker 11)

The holistic and educative approach taken by these practitioners, and their resulting impact on patient/client quality of life was also seen as vitally important:

'They [CS and AP] are taking on functions that obviously are functions of nursing but may previously have been conducted by medical students or... the therapies... we get a more holistic intervention when it's housed within one professional'.

(Policy-maker 1)

'[CS]... providing a real continuity of care... providing the information the patients need. It makes a huge difference to their actual quality of life... much more informative. Much more explaining. Much more complete'.

(Policy-maker 2)

The advanced practitioners were appreciated for their evidence-based clinical knowledge that the participants in contact with them had been able to source. Three participants commented that there was potential for a reduction in litigation and a better safety focus:

'... that's been seen the world over, that there's been a decrease in the litigation in relation to advanced practice. That they have been very safe practitioners. That's for sure'.

(Policy-maker 5) 
Other participants highlighted innovative clinical initiatives stimulated or brought about by advanced practitioners, which had led the field in Ireland:

' $\ldots$ the work on ionizing radiation that was done in advance of even the HSE or anyone else deciding that the scope of practice needed to be looked at and expanded. They [ANPs in one hospital] had a programme built and were delivering it... very effectively and they were an enormous resource when... the legislation was confirmed that nurses could request ionizing radiation'.

(Policy-maker 6)

Comments were made on the need to expand clinical specialist and advanced practitioner roles across the country, to enable all to experience quality care. Two participants had concerns around the introduction of specialist and advanced roles, and cautioned that they might hinder the development of more junior staff:

'The clinical nurse specialist... if we don't get it right, there can be some tension and friction between the staff nurse, and what we want to do is develop the capacity of all nurses'.

(Policy-maker 9)

'... when you shine a bright light into one area it casts everything else into darkness... other colleagues feel de-skilled, feel lesser... and they step back'.

(Policy-maker 4)

These fears, however, are tempered by the views of the majority of participants as to how well the CSs/ APs mentor and educate their colleagues.

\section{Clinical leadership role}

Participants believed that clinical specialists/advanced practitioners were often leaders within their organisation or micro-system, and needed to be strong, wellprepared nurses. However, they also felt that advanced practitioners did not always get the recognition that they deserved:

'Pushing out the boundaries of nursing and providing... leadership in healthcare organisations... to keep the best, most competent and skilled nurses at the bedside'.

(Policy-maker 5)
I think that they're [ANPs] leaders in nursing, okay, but I'm not sure they are seen as it, because of their clinical work'.

(Policy-maker 1)

'... [mental health nurses] are moving away from hospitals out into the community... you would only send pioneers out there ... they need to be very well equipped... exceptional strong nurses and that often describes CNSs'.

(Policy-maker 4)

Numerous comments were made about how the clinical specialists/advanced practitioners demonstrated strong clinical leadership by being at the forefront of practice, leading in aspects such as guideline development and new care initiatives:

'If there's... a change in practice, that they [CNS] are very good to take it on as to what should happen and develop guidelines around that'.

(Policy-maker 2)

'The majority of expertise in this type of guideline development is with CNSs and ANPs'.

(Policy-maker 1)

'In terms of policy and guideline development and the mental health service in general, I think it's fair to say that it's being led by the nursing profession'.

(Policy-maker 10)

Participants also highlighted the potential for clinical specialists/advanced practitioners to become involved in the development of national guidelines, so that their expertise could be spread to other areas where clinical specialists/advanced practitioners were not employed:

'... involved in guideline development, so I think... it's a resource that should be built on, not just ... locally. It should be accessed nationally'.

(Policy-maker 3)

The majority of participants spoke of the amount of formal and informal education of other staff undertaken by clinical specialists/advanced practitioners, including teaching medical students and junior doctors:

'... their ability to educate the junior staff. You know, the huge resource they [CNS] are for the 
new people [junior doctors] coming in every 6 months, new consultants coming in'.

(Policy-maker 2)

'I have involved some of the specialized midwives in giving formal lectures to the medical students... in... blood transfusion, infectious diseases... they certainly have a role in medical undergraduate education'.

(Policy-maker 7)

In particular, the level, quality and clinical application of their teaching was highly praised:

'The amount of teaching they are doing is phenomenal... the rest of us are just talking about what we're reading in books. Whereas these guys are actually able to really teach about their particular area... That's growing our next generation of nurses'.

(Policy-maker 1)

\section{Professional leadership role}

Leadership at a higher and wider level was discussed by all the participants, with favourable comments made on the strategic leadership demonstrated by, in particular, the advanced practitioners. This was demonstrated through committee membership and the publication of scholarly papers:

'I would be... aware of them being on committees at international level... across Europe and... we were delighted that... we had all nurses and midwives prescribing, which was unique worldwide'.

(Policy-maker 5)

'Many of those who have excelled... some of them are obviously writing papers and, you know, developing some sort of international kind of kudos'.

(Policy-maker 12)

Suggestions were made as to how such leadership potential could be harnessed and supported to encourage the career progression of clinical specialists/ advanced practitioners. One participant believed that these expert clinicians would be ideally prepared to take on top jobs in key positions in healthcare management in the future:

'There really should be some sort of recognized career progression or vocational management training for those who... really have the acumen and show the interest because... these are the kind of people who, in other countries 5-8 years down the line could be chief executives, if we developed them correctly... [they] understand the challenges in managing [that] we don't understand'.

(Policy-maker 3)

\section{Research and audit role}

All policy-makers interviewed believed that research was an important element of the advanced practitioner's function but acknowledged the difficulties they encountered. Collaboration and support were identified as key to research output:

'... they had enormous strength in audit alright. They could turn their hand to auditing overnight... I found that research wasn't as strong as I would have expected... I think that comes down to a time constraint and not having the support in relation to being able to do it, because they're very intelligent, capable people'.

(Policy-maker 6)

Suggestions were made as to why research output might be low, including a lack of time, clinical demands and disparaging comments from other colleagues:

'I can understand perfectly why they [ANPs] don't have the time [for research]... It's not a priority in their day-to-day... we might think it's necessary, but when you're on the ground in this difficult environment right now, it is not a priority. You are lucky if quality of care is a priority'.

(Policy-maker 5)

'I see nursing research as hugely valuable but it often gets pooh-poohed by the medical profession because it's not published in New England Journal and the likes'.

(Policy-maker 2)

There was also a concern that research output was not always visible and activity was slowed by the need for approval from ethics committees. Participants suggested that research output might be improved by protected time, and a stronger link between practice and academia, including the appointment of joint chairs in nursing or midwifery. 


\section{Financial implications of the role}

There was acknowledgement that lack of resources, including budget cuts, a government-applied moratorium on recruitment and budget-holders' interest in immediate monetary savings, was an issue that hampered the development of the clinical specialist/ advanced practitioner roles:

'I would be very encouraging of the ongoing development of the midwife specialist and I would like to see it expanded in due course... resources permitting [laughs]'.

(Policy-maker 7)

'We have a moratorium [on recruitment] at the moment... That complicates everything we do. But... if somebody comes and says they want to do a joint appointment, well, let's look at it and see how we can work around it'.

(Policy-maker 1)

'It's purely what it costs... and how they can save on that cost at the moment, whether the patient ends up coming back ten times into A\&E or into the hospital is irrelevant [to funders]. I think all of that has never been taken into the equation'.

(Policy-maker 5)

A few participants, who were nursing policy-makers at a lower level than other participants, spoke of the difficulty of persuading budget-holders of the added value of the advanced practitioner role, despite the evidence available. One person explained how nursing budgets were sometimes used to fund advanced posts that did not appear to be focused on nursing care:

'We have nurses who look more like psychologists than our clinical psychologists do... they have morphed into a whole variety of different things... so if the budget for nursing, for example, is paying for a whole load of staff who are actually delivering a psychology-type service, that's [a problem] ... we need to rewire the system'.

(Policy-maker 4)

Some suggestions for circumventing the lack of funding included seeking research funds and using technology to support care-giving. The costs of specialist and advanced services was discussed by the participants. The majority believed that, even if services cost more initially, they would become more costeffective due to increased clinical effectiveness:
'I have been able to delegate a lot of the first visit appointments to the specialist. So, they certainly have been able to replace medical hours for outpatient colposcopy diagnosis and treatment'.

(Policy-maker 7)

' $\ldots$ because of their skills, they do it better... I think they add huge value... it's far more costeffective'.

(Policy-maker 2)

'If you looked at errors and... infections and all those... quality things... I think the service is certainly, probably, more cost-effective in the long-run'.

(Policy-maker 6)

\section{Challenges to introduction of clinical specialist/ advanced practitioner roles}

Challenges that participants saw in introducing clinical specialist/advanced practitioner roles, including medical fears of overlapping roles, and lack of support, were mentioned briefly:

'There's a great deal of paranoia among the medical profession initially looking at enhancing the nurse's role in the context of mental health service, certainly'.

(Policy-maker 12)

'As policy-makers we haven't given enough guidance and maybe support in some ways to nurses in their roles as ANPs and CNSs'.

(Policy-maker 8)

Recommendations from policy-makers for the development of CS/AP posts included the need for extensive dialogue with all clinicians prior to the introduction of the roles, strong clinical governance and guidelines on collaborative decision-making - all suggestions in agreement with the present site preparation required by the National Council for advanced practitioner posts (NCNM 2008b). In addition, the long-term and wider implications of introducing these roles in terms of workforce planning were mentioned. In particular, in relation to advanced practitioners taking on some of the tasks traditionally performed by medical doctors as roles and services evolve, one participant emphasized the need for planning ahead:

'... huge implications for workforce planning... if you have advanced practitioners taking on roles 
particularly outside of the traditional midwifery, well then we are going to need more midwives... running antenatal clinics... you may not need to have as many obstetricians in the outpatients'.

(Policy-maker 7)

\section{Future directions for clinical specialist/advanced practitioner roles}

Policy-makers emphasized the important contribution that clinical specialists/advanced practitioners could make to the transformation agenda for health within Ireland. They suggested there would be a major focus on patient/client safety, that recent policy initiatives would result in a re-orientation of services, and that CSs/APs had a critical role to play in this:

'Many of the consultants... [are] leading the national integrated programmes for COPD or heart failure, emergency medicine... and the roles of CNSs and ANPs are certainly going to be critical to their successes'.

(Policy-maker 8)

'If you looked at an individual with an intellectual disability and a mental health problem, there's huge scope for a nurse-led service and an ANP role in that'.

(Policy-maker 12)

Developments within the area of chronic-disease management were emphasized as important, as was the need for services that link hospital and community and areas with less medical support:

'The area of chronic-disease management, immunization... primary care, are all areas where I think there's substantial scope for further development of the role'.

(Policy-maker 11)

'The nurse specialists would tell me lots more they could do if we had the resources as an outreach. Many of them could actually be working out in the community'.

(Policy-maker 8)

'I would like to see more of them in the community, more of them in elderly care, because those are the areas that you don't have the medical support and we don't see them in mental health too much or in ID [intellectual disability] or paediatrics'.
(Policy-maker 5)

Others emphasized the need for creative, flexible, supportive environments that allow practitioners to develop, if these valuable staff are to be retained.

'[re ANPs]... we're attracting a more cerebral nurse... unless you satisfy that need in them, you will lose them from the profession altogether. If you are going to drop them into a very controlled suffocating environment, you are wasting your time'.

(Policy-maker 4)

\section{Summary}

The participants' overall impression of the contribution made by clinical specialists/advanced practitioners was mainly positive. There appeared to be benefits at both practitioner levels from their clinical practice, clinical leadership and audit roles. The clinical specialists and advanced practitioners were said to demonstrate professional leadership at local level, and the advanced practitioners were contributing nationally and internationally also. The advanced practitioners, and some clinical specialists, were described as being active in research. There was acknowledgement that lack of resources hindered development of clinical specialist/advanced practitioner roles, and the majority believed that the roles were cost-effective due to increased clinical effectiveness.

Participants described some challenges to the introduction of CS/AP roles including medical fears of diminished roles, and a lack of support from colleagues. They recommended extensive dialogue with all clinicians prior to the introduction of the roles, strong clinical governance, guidelines on collaborative decision-making and workforce planning.

Also discussed were the future directions for CS/AP roles, in particular in relation to the contribution they could make to the planned re-orientation of services in the HSE. Their important role in chronic-disease management was emphasized, as was the need for them to be employed in services linking hospital and community, and in areas with less medical support.

\section{Discussion}

The registration and accreditation process for advanced practitioners and approval process for clinical specialists is of inestimable value in terms of 
building relationships and appears to have resulted in a supportive environment for clinical specialist/ advanced practitioner posts that makes Ireland the envy of other countries. Advanced practice was unanimously endorsed by all participants. Similar endorsement from Irish health policy documents (Health Service Executive 2010) clearly shows the esteem in which these practitioners are held, similar to research from other countries (Newhouse et al. 2011). Fears expressed in the UK regarding the adverse effect that specialist/advanced posts had on ward sister and charge nurse roles, due to nurse specialists receiving the same pay and a perceived higher status (Royal College of Nursing 2009) were not described by these policy-makers.

Policy-makers identified direct care as a key role for CSs/APs, resulting in improved patient/client outcomes. Numerous studies worldwide have found similar results. For example, McCorkle et al. 2000's randomized trial of 375 elderly patients with cancer shows that advanced practitioner intervention resulted in more of those with late-stage cancer in the experimental group $(n=48,67 \%)$ surviving for two years, compared with the control group $(n=19,40 \%)$. Although it is appropriate to compare clinical specialist/advanced practitioner's care with medical practice when their role is one of medical substitution (Coster et al. 2006), this ignores the measurement of traditional nursing skills such as counselling, teaching and co-ordinating services (Ingersoll et al. 2000).

The greater organisational skills and increased holistic and educative approaches taken by CS/APs in Ireland were described by policy-makers in this study. Their role was said to have an impact in terms of swifter patient/client access to services, views similar to those found in a study interviewing nine key stakeholders from an accident and emergency department in one UK region (Tye \& Ross 2001). Better continuity of care and follow-up, leading to improved care and compliance were also described in the present study, similar to work in acute care areas in America (Kleinpell 2005) and Canada (van Soeren \& Micevski 2001), and in neonatal examination in the UK (Lee et al. 2001).

Numerous comments were made by the participants about the clinical specialist/advanced practitioners' clinical leadership, described as being at the forefront of practice, and leading guideline development and new initiatives in care. Very little international literature identifies evidence of this, although some do note leadership as an aspect of the advanced practitioners' role (Carryer et al. 2007, Mantzoukas \& Watkinson 2007, Spross \& Lawson 2009).
Similarly, other sections of the SCAPE study showed greater leadership strengths in advanced practitioners (Begley et al. 2012, Elliott et al. 2012), and further detailed discussion is included there. Formal and informal education of healthcare staff was also undertaken by clinical specialists/advanced practitioners, a role aspect demonstrated in other countries also (van Soeren \& Micevski 2001, Kleinpell \& Gawlinski 2005).

The policy-makers described the clear ability of advanced practitioners to embrace professional leadership through active engagement in policy development. Such traits have not, however, been identified clearly in the international literature, although the Canadian Nurses Association national framework for advanced nursing practice (Canadian Nurses Association 2008) does describe their role as informing policy-makers, advocating for patients/clients and the community and influencing health policy. The policymakers believed that advanced practitioners lacked administrative support and resources, and had competing demands that prevented them from fulfilling research aspects of their role completely. Audit was said to be a common output, however, and the potential for increased research is present in the fact that all advanced practitioners in Ireland must hold Master's degrees (NCNM 2008b). The conduct of research is an expectation of advanced practitioners only (not clinical specialists), in common with descriptions world-wide of advanced practice roles (Manley 1997, Mantzoukas \& Watkinson 2007, Kring 2008, Spross \& Lawson 2009).

There was acknowledgement that budget cuts, a government-applied moratorium on recruitment, and budget-holders' interest in immediate monetary savings hampered the development of the CS/AP roles. This was despite their view that CS/AP care was more cost-effective, which has been seen in some (but not all) other studies (Dunn 1997, Cowan et al. 2006), prompting the statement that further economics research needs to be conducted (Horrocks et al. 2002). Recent work in the UK by the Office for Public Management has highlighted the savings that can be made by investing in specialist posts (Office for Public Management 2012).

Challenges in terms of acceptance of the roles by multidisciplinary team members were also mentioned, an issue noted internationally also (Norris \& Melby 2006, O'Connor 2008, Por 2008, Lindblad et al. 2010, Kilpatrick et al. 2011). Strategic, operational and organisational constraints, however, (Livesley et al. 2009, Barton \& Mashlan 2011) were not noted in this study. 


\section{Implications for nurse and midwife managers}

The important contribution CSs/APs could make to the HSE transformation agenda in future was emphasized, in particular the need to re-orientate services towards chronic-disease management and community care (HSE 2006). The HSE's national service plan in the area of chronic disease management (HSE 2010) includes the development and expansion of the role of the CNSs and ANPs, as does a recent report on plans for the reconfiguration of acute hospital services in the south-west region of Ireland (Higgins 2010). ANPs are also listed as key team members in the National Cancer Screening Service (NCSS) plan for a colorectal cancer screening programme (NCSS 2009). Since this study was conducted the numbers of advanced practitioner posts have increased from 69 in 2008 (nursing 68, midwifery 1) (NCNM 2008a) to 102 (nursing 98; midwifery 4) in December 2011 (An Bord Altranais 2011). The total number of CNS/CMSs in 2008 was 2032 (nursing - 1966; midwifery - 66) (NCNM 2008a); this increased to approximately 2053 in December 2011 (An Bord Altranais, personal. communication., 2012). Data from economic studies of clinical specialist/advanced practitioner roles needs to be highlighted to key budget-holders and further posts sought.

\section{Conclusion}

Ireland is unique in the comprehensive registration process set up to register and accredit all advanced practitioner posts and practitioners in the country (NCNM 2008b), now overseen by An Bord Altranais. The process involves the service area and multidisciplinary team members working together in preparing the post, which encourages service areas to demonstrate support of the role. The clinical specialist posts are approved (not accredited) under a similar system, with agreed criteria (NCNM 2008a).

These healthcare policy-makers believed that clinical nurse and midwife specialists and advanced nurse and midwife practitioners in Ireland had the capacity to be leaders, particularly at a strategic level, and played a central role in enhancing the quality and continuity of care. They were strongly in support of the roles and thought that they could make an important contribution to future health service developments. In particular, it was stated that more advanced practice posts were required in the areas of chronic-disease management, community care and where medical support was slight. Given such strong support from key policy-makers, it is likely that CS/AP roles will prosper in Ireland, with a resulting impact on quality care.

\section{Acknowledgements}

We thank the key policy-makers who took part in interviews. A special thank you to the Schools of Nursing and Midwifery in Trinity College Dublin and National University of Ireland, Galway for support, and the SCAPE study team, including our external advisors Kate Gerrish, Susan McLaren, Ian Norman, Ruth Kleinpell and Michelle Beauchesne. We are grateful to the National Council for the Professional Development of Nursing and Midwifery in Ireland for funding this study and for assisting with information and recruitment. A special word of thanks to Celena O’Brien, Project Manager, for all her assistance with the study.

\section{Source of Funding}

The National Council for the Professional Development of Nursing and Midwifery in Ireland commissioned and funded this study.

\section{Ethical Approval}

Faculty of Health Sciences, Trinity College Dublin (no number).

\section{Author contributions}

All authors obtained funding and took part in the study conception and design. All authors collected qualitative data and took part in data analysis. $\mathrm{CB}$ drafted the manuscript and $\mathrm{KM}, \mathrm{AH}$ and $\mathrm{AC}$ made critical revisions to the paper for important intellectual content. All authors agreed the final version to be published.

\section{References}

An Bord Altranais (2011) Register Statistics 2011. Available at: http://www.nursingboard.ie/en/statistics_article.aspx?article $=f 8504 f 5 d-c 62 c-4 c 99-a 3 b 3-b d 2 c 050 c 53 f 5$, accessed 25 March 2012.

Barton D. \& Mashlan W. (2011) An advanced nurse practitioner-led service - consequences of service redesign for managers and organizational infrastructure. Journal of Nursing Management 19 (7), 943-949.

Begley C., Murphy K., Higgins A., et al. (2010) An Evaluation of Clinical Nurse and Midwife Specialist and Advanced Nurse and Midwife Practitioner Roles in Ireland (SCAPE). National Coun- 
cil for the Professional Development of Nursing and Midwifery in Ireland, Dublin.

Begley C., Elliott N., Coyne I., Higgins A., \& Comiskey C. M. (2012) Differences between clinical specialist and advanced practitioner clinical practice, leadership, and research roles, responsibilities, and perceived outcomes (the SCAPE study). Journal of Advanced Nursing. doi:10.1111/j. 1365-2648.2012.06124x.

Bergen A. \& While A. (2005) 'Implementation deficit' and 'street-level bureaucracy': policy, practice and change in the development of community nursing issues. Health and Social Care in the Community 13 (1), 1-10.

Brook S. \& Rushforth H. (2011) Why is the regulation of advanced practice essential? British Journal of Nursing 20 (16), 996, 998-1000.

Bryant-Lukosius D., DiCenso A., Browne G. \& Pinelli J. (2004) Advanced practice nursing roles: Development, implementation and evaluation. Journal of Advanced Nursing 48 (5), 519-529.

Canadian Nurses Association (2008) Advanced Nursing Practice: A National Framework. Canadian Nurses Association, Ottawa.

Carryer J., Gardner G., Dunn S. \& Gardner A. (2007) The core role of the nurse practitioner: practice, professionalism and clinical leadership. Journal of Clinical Nursing 16 (10), 18181825.

Coster S., Redfern S., Wilson-Barnett J., Evans A., Peccei R. \& Guest D. (2006) Impact of the role of nurse, midwife and health visitor consultant. Journal of Advanced Nursing 55 (3), 352-336.

Cowan M.J., Shapiro M., Hays R.D. et al. (2006) The effect of a multidisciplinary hospitalist/physician and advanced practice nurse collaboration on hospital costs. Journal of Nursing Administration 36 (2), 79-85.

DiCenso A., Bryant-Lukosius D., Martin-Misener R. et al. (2010) Factors enabling advanced practice nursing role integration in Canada. Nursing Leadership 23, 211-238.

Donald F., Bryant-Lukosius D., Martin-Misener R. et al. (2010) Clinical nurse specialists and nurse practitioners: title confusion and lack of role clarity. Nursing Leadership 23, 189-201.

Dorey P. (2005) Policy Making In Britain: An Introduction. Sage Publications, London.

Dunn L. (1997) A literature review of advanced clinical nursing practice in the United States of America. Journal of Advanced Nursing 25 (4), 814-819.

Elliott N., Higgins A., Begley C., Lalor J., Sheerin F., Coyne I. \& Murphy K. (2012) The identification of clinical and professional leadership activities of advanced practitioners: findings from the specialist clinical and advanced practitioner evaluation study in Ireland. Journal of Advanced Nursing. doi:10.1111/j. 1365-2648.2012. 06090.x.

Glaser B. (1978) Theoretical Sensitivity: Advances in the Methodology of Grounded Theory. Sage, Mill Valley, CA.

Government of Ireland (1998) Report of the Commission on Nursing. The Stationery Office, Dublin.

Hall W. \& Callery P. (2001) Enhancing the rigor of grounded theory: incorporating reflexivity and relationality. Qualitative Health Research 11 (2), 257-272.

Health Service Executive (2006) A National Chronic Disease Management Patient Support Programme for HSE: Report of the National Steering Committee. HSE, Naas, Ireland.

Health Service Executive (2010) National Service Plan. HSE, Naas, Ireland.
Higgins J.R. (2010) Reconfiguration of Acute Hospital Services, Cork and Kerry. HSE South (Cork and Kerry), Cork.

Horrocks S., Anderson E. \& Salisbury C. (2002) Systematic review of whether nurse practitioners working in primary care can provide equivalent care to doctors. British Medical Journal 324 (7341), 819-823.

Ingersoll G.L., McIntosh E. \& Williams M. (2000) Nurse-sensitive outcomes of advanced practice. Journal of Advanced Nursing 32 (5), 1272-1281.

Jones M.L. (2005) Role development and effective practice in specialist and advanced practice roles in acute hospital settings: systematic review and meta-synthesis. Journal of Advanced Nursing 49 (2), 191-209.

Kennedy F., McDonnell A., Gerrish K., Howarth A., Pollard C. \& Redman J. (2011) Evaluation of the impact of nurse consultant roles in the United Kingdom: a mixed method systematic literature review. Journal of Advanced Nursing 68 (4), 721-742.

Kilpatrick K., Lavoie-Tremblay M., Ritchie J.A., Lamothe L. \& Doran D. (2011) Boundary work and the introduction of acute care nurse practitioners in healthcare teams. Journal of Advanced Nursing 68 (7), 1504-1515.

Kitto S.C., Chesters J. \& Grbich C. (2008) Quality in qualitative research. Medical Journal of Australia 188 (4), 243-246.

Kleinpell R. (2005) Acute care nurse practitioner practice: results of a 5-year longitudinal study. American Journal of Critical Care 14 (3), 211-219.

Kleinpell R. \& Gawlinski A. (2005) Assessing outcomes in advanced practice nursing practice. The use of quality indicators and evidence-based practice. American Association of Critical-Care Nurses 16 (1), 43-57.

Kleinpell R.M., Hudspeth R., Scordo K.A. \& Magdic K. (2012) Defining NP scope of practice and associated regulations: Focus on acute care. Journal of the American Academy of Nurse Practitioners 24 (1), 11-18.

Kring D.L. (2008) Clinical nurse specialist practice domains and evidence-based practice competencies: a matrix of influence. Clinical Nurse Specialist 22 (4), 179-183.

Lee T.W.R., Skelton R.E. \& Skene C. (2001) Routine neonatal examination: effectiveness of trainee paediatrician compared with advanced neonatal nurse practitioner. Archives of Disease in Childhood. Fetal and Neonatal Edition 85 (2), F100-F104.

Lindblad E., Hallman E.B., Gillsjö C., Lindblad U. \& Fagerström L. (2010) Experiences of the new role of advanced practice nurses in Swedish primary health care - a qualitative study. International Journal of Nursing Practice 16 (1), 69-74.

Livesley J., Waters K. \& Tarbuck P. (2009) The management of advanced practitioner preparation: a work-based challenge. Journal of Nursing Management 17 (5), 584-593.

Lowe G., Plummer V., O’Brien A.P. \& Boyd L. (2012) Time to clarify - the value of advanced practice nursing roles in health care. Journal of Advanced Nursing 68 (3), 677-685.

Manley K. (1997) A conceptual framework for advanced practice: an action research project operationalizing an advanced practitioner/consultant nurse role. Journal of Clinical Nursing 6 (3), 179-190.

Mantzoukas S. \& Watkinson S. (2007) Review of advanced nursing practice: the international literature and developing the generic features. Journal of Clinical Nursing 16 (1), 28-37. 
Mays N. \& Pope C. (2000) Qualitative research in health care: assessing quality in qualitative research. British Medical Journal 320, 50-52.

McCorkle R., Strumpf N.E., Nuamah I.F. et al. (2000) A specialized home care intervention improves survival among older post-surgical cancer patients. Journal of the American Geriatrics Society 48 (12), 1707-1713.

National Cancer Screening Service (2009) Implementing Ireland's First National Population-based Colorectal Cancer Screening Programme Available at: http://www.cancerscreening.ie/publications/ImplementingColorectalProgramme.pdf, accessed 3 June 2012.

National Council for the Professional Development of Nursing and Midwifery (NCNM) (2008a) Framework for the Establishment of Clinical Nurse/Midwife Specialist Posts, 4th edn. NCNM, Dublin.

National Council for the Professional Development of Nursing and Midwifery (NCNM) (2008b) Accreditation of Advanced Nurse Practitioners and Advanced Midwife Practitioners. NCNM, Dublin.

Newhouse R.P., Stanik-Hutt J., White K.M. et al. (2011) Advanced practice nurse outcomes 1990-2008: a systematic review. Nursing Economics 29 (5), 230-250.

Norris T. \& Melby V. (2006) The Acute Care Nurse Practitioner: Challenging existing boundaries of emergency nurses in the United Kingdom. Journal of Clinical Nursing 15 (3), 253-263.

O'Connor T. (2008) What's happening with nurse practitioners? Nursing New Zealand 14 (3), 11-13.

Office for Public Management (2012) How managing oxygen therapy in the community can save up to $11.1 \mathrm{~m}$ per annum and improve quality of life for patients. Available at: http://
www.rcn.org.uk/_data/assets/pdf_file/0008/376712/OPM_ Case_Study_-_Cheshire_Respiratory_Support.pdf, accessed 3 June 2012.

Por J. (2008) A critical engagement with the concept of advancing nursing practice. Journal of Nursing Management 16 (1), 84-90.

Pulcini J., Jelic M., Gul R. \& Yuen Loke A. (2010) An international survey on advanced practice nursing education, practice, and regulation. Journal of Nursing Scholarship 42 (1), 31-39.

Roberts J., Floyd S. \& Thompson S. (2011) The clinical nurse specialist in New Zealand: how is the role defined? Nursing Praxis New Zealand 27 (2), 24-35.

Royal College of Nursing (2009) Breaking Down Barriers, Driving Up Standards: The Role of the Ward Sister and Charge Nurse. Royal College of Nursing, London.

Sheer B. \& Wong F.K.Y. (2008) The development of advanced nursing practice globally. Journal of Nursing Scholarship 40 (3), 204-211.

van Soeren M.H. \& Micevski V. (2001) Success indicators and barriers to acute nurse practitioner role implementation in four Ontario hospitals. AACN Clinical Issues: Advanced Practice in Acute and Critical Care 12 (3), 424-437.

Spross J.A. \& Lawson M.T. (2009) Conceptualizations of advanced practice nursing. In Advanced Practice Nursing. An Integrative Approach, 4th edn (A.B. Hamric, J.A. Spross \& C.M. Hanson, eds), pp. 33-74. Saunders Elsevier, St Louis.

Tye C.C. \& Ross F.M. (2001) Blurring boundaries: professional perspectives of the emergency nurse practitioner role in a major accident and emergency department. Journal of Advanced Nursing 31 (5), 1089-1096. 